\title{
The Saluting Battery at the Castle of Good Hope Cape Town 1910-1942
}

\section{Cdr W.M. Bisset*}

Although the guns of the Castle of Good Hope in Cape Town never fired a shot in anger, they often fired salutes in honour of Royalty (the King's Birthday), visiting heads of state and warships, Union Day (a salute of 19 guns in 1931) and on other appropriate occasions. The subject of this article is the Saluting Battery on Katzenellenbogen Bastion at the Castle which was operational from about 1910 until about 1942. In 1912 the Castle was the only authorized saluting station in the Union of South Africa. ${ }^{1}$ The battery was manned by personnel of the Royal Garrison Artillery until it was taken over by South Africa in 1921.

Whilst there are doubtless many people who remember the Castle's saluting battery, there would appear to be relatively few documents on this topic in the SA Defence Force archives. Letters dated 26 May 1931 and 11 May 1932 on the subject of salutes refer to the ' $6 \mathrm{Pdr}$ Saluting Battery, The Castle.' The former letter was signed by Lt (later Brig) M. de Villiers. A good photograph of the battery being manned by gunners of No 1 Company, SA Permanent Garri- son Artillery was taken by Cay's Photo Service but the copyright holder cannot be traced so it cannot be reproduced. This photograph is now in the Editorial Library of The Argus in Cape Town. Fortunately another photograph of the battery has survived and can be reproduced. It was taken by Mr Arthur Elliott and is now in the Cape Archives Collection

Restoration work on the Castle of Good Hope has been underway for a number of years and the present writer was asked to attempt to trace as much information concerning the saluting battery and its guns as possible in the hope that similar guns could be found and mounted in the empty emplacements, which are shown to the visitors who are taken on a guided tour of the building

WOI P.A. Swart, who served at the Castle from 1934-1936 responded to the press appeal and wrote that the guns were four 12-pdr $12 \mathrm{cwt}$ quick firing guns on P1 naval mountings. He recalled that a salute of 21 guns was fired whenever HE the Governor-General arrived by train in

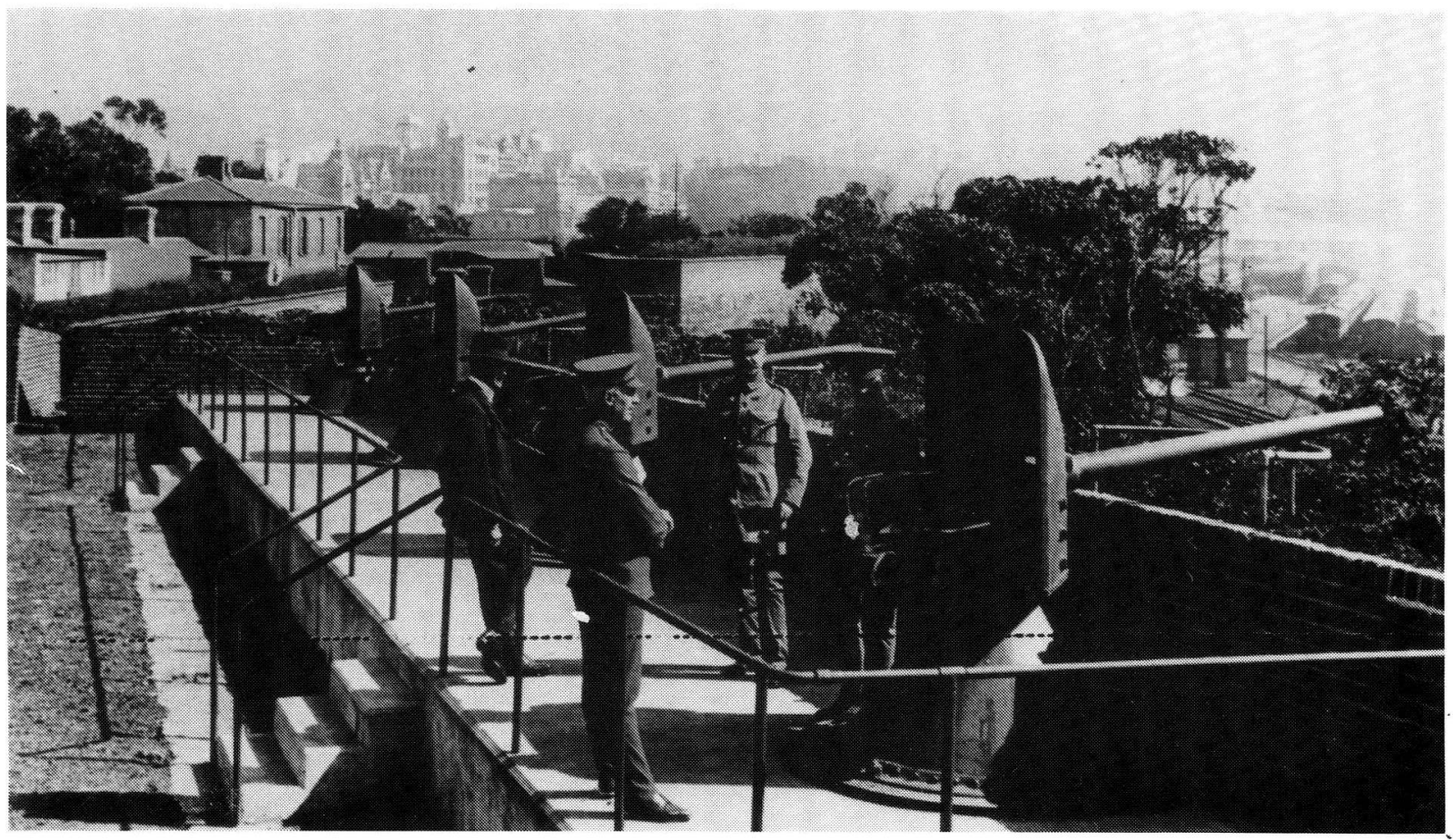

British Army personnel at the saluting battery on Katzenellenbogen Bastion at the Castle circa 1912. The guns are Hotchkiss QF 6-pounders. 
Cape Town from Pretoria. Salutes of 19 guns were fired whenever warships entered the Table Bay harbour.

The fact that the four saluting guns were 12-pdrs was confirmed by the late Brig $\mathrm{M}$. de Villiers in an article in Commando in August 1953. ${ }^{2}$

A recently discovered file on the Saluting Battery at the Castle reveals that the registered numbers of the garrison carriages (also known as cone pedestal mountings) of the four 6-pdr Hotchkiss Quick Firing recoil Mk I guns were A1225 (No 1 gun), A1228 (No 2 gun) A1230 (No 3 gun) and A1226 (No 4 gun). All four guns were manufactured by the Maxim Nordenfelt Company in 1891.

No 3 gun (A1230) was erected at the Castle in Cape Town in August 1910. No 1 gun (A1225), No 2 gun (A1228) and No 4 gun (A1226) were originally mounted at Fort Wynyard in Green Point but were moved to the Castle in August 1910. All four guns remained there until 1942. The last entry in the Records of Rounds firec columns reads 'Castle : 21.4.42:5 Blank Powder' except for No 4 gun which used only 4 Blank Powder

The file cover containing the Memoranda of
Examination (Army Form G 835) is marked Robben Island and as similar guns from Lower North Battery were moved to the Coast Artillery Training Centre on Robben Island it seems likely that these guns may also have been moved there.

Why Cape Town's Saluting Battery was moved from the Castle to Lion Battery is not known. However salutes had been fired from Lion Battery on at least three occasions prior to the move namely on the death of HM King George V, the accession of HM King Edward VIII and on the departure of HE the President of Portugal by ship on 21 August 1939. Between 1936 and 1939 the Cape Town foreshore was reclaimed and the sea was now much further away. During the Second World War Katzennellenbogen Bastion was armed with one 40-mm Bofors gun which was mounted close to the Saluting Battery. The exciting discovery of the file on the guns which was saved from destruction by WOI H.J.R. Kokott encourages one to hope that more information may yet be traced.

${ }^{\star}$ Cdr W.M. Bisset is OC Naval Museums and Military Museums WF Command.

\section{Endnotes}

1. The King's Regulations and Orders for the Army 1912, p 351

2. 'M.V.' (Brig M. de Villiers) 'Those were the days, Chapter I' in Commando, August 1953, p41. 